\title{
A Dona da Brincadeira: televisão e brinquedos na produção cultural da infância contemporânea*
}

Juliana Pereira de Sousa

Mestra em Comunicação e Linguagens (UTP) e especialista em Marketing (PUC-PR).

É coordenadora e professora do Curso Superior de Tecnologia em Design Gráfico do Centro Universitário Curitiba (Unicuritiba). Sócio nucleado Intercom (comunicação e educação).

E-mail: juli.cp@uol.com.br

Resumo: O presente artigo reconhece o brinquedo como um objeto de comunicação capaz de traduzir a identidade da infância contemporânea circunscrita pela sociedade midiática. Verifica-se a participação do brinquedo como produto da indústria cultural infantil, integrando-o a um possível sistema de moda, de consumo do efêmero e das imagens vistas na TV.

Palavras-chave: comunicação, televisão, brinquedos, consumo, As Meninas Superpoderosas.
Abstract: This article recognizes the toy as an object of communication capable of translating the identity of contemporary childhood circumscribed by the media. It is the participation of the toy industry as a cultural-integrating the child to a possible system of fashion, consumption and the fleeting images seen on TV.

Keywords: communication, television, toys, consumption, The Powerpuff Girls.

Em 1998, uma matéria publicada no caderno especial Folhinha do jornal Folha de S. Paulo trazia na capa a chamada: "O sonho vira brinquedo - saiba como seu desejo é transformado em brinquedo e de que forma você é convencido a comprar esses produtos". A matéria publicada com o título Cinema inspira fabricantes revelava o sucesso de algumas empresas ao adotar para fabricação personagens dos desenhos animados: "Os fabricantes procuram nos filmes de cinema, nas histórias em quadrinhos e na TV os personagens que fazem sucesso entre as crianças. Na TV, eles consideram ainda a audiência que o programa tem" ${ }^{2}$. Dentro desse contexto, a televisão modificou o brinquedo suscitando novas percepções, transformando-o em produto de uma indústria da imagem. Por sua vez, a criança espectadora, para quem se entrega a chave do imaginário, tornou-se um ator, não só porque ela brinca e representa, mas também porque a televisão ofereceu o palco do seu universo lúdico. Multiplicando o emprego da imagem, criou-se uma linguagem inteligível e atraente para a criança.

Recebido: 17.03.2009

Aprovado: 22.06.2009

* Este artigo é proveniente de uma face da dissertação Televisão e brinquedos-personagens: mediações simbólicas Superpoderosas? Ver: SOUSA J. P. Televisão e brinquedos-personagens: mediações simbólicas Superpoderosas? 1. ed. Curitiba: JPS, 2009. 100 p.

1. CINEMA inspira fabricantes. Folha de S. Paulo, São Paulo, p. 4, 7 mar. 1998. Folhinha. 
2. Ibid., p. 5 .

3. PRIORE, M. D. (Org.). História das crianças no Brasil. São Paulo: Contexto, 2000 .

4. WOLF, M. Teorias da comunicação. Portugal: Presença, 1999. p. 108

5. Ibid., p. 108

6. SODRÉ, M. Antropológica do espelho. Rio de Janeiro: Vozes, 2002.
À medida que os programas de televisão foram se especializando em produções para o público infantil e, sobretudo, na tecnologia da computação gráfica, que permitiu a criação de desenhos animados dirigidos a tal audiência, pôde-se observar o advento de fatores que inauguraram um modo de infância próprio das cidades contemporâneas. Intensamente ligada à natureza de produto industrial e a um ritmo de consumo cotidiano, a televisão passou a fazer parte da vida e do imaginário das crianças, oferecendo a elas um conjunto de referências imaginárias representadas pelos personagens em universos fantásticos capazes de englobar significados e valores que surgem e se difundem nos grupos e nas práticas sociais.

As produções infantis veiculadas pela mídia televisão passaram a oferecer às crianças uma alternativa de diversão e lazer em uma sociedade crescentemente urbana, que já não dispõe de espaços naturais ou segurança suficientes para permitir o brincar livremente de bola, amarelinha, pega-pega. Elas estão cercadas em condomínios ou em playgrounds de edifícios, em quadras de grama sintética, sob a vigilância de um adulto, em espaços artificiais³.

O brinquedo surge como simulacro da imagem da televisão, estabelecendo uma conexão entre a criança e o sistema midiático vigente. Apresenta-se como produto exterior ao meio que lhe dá origem (a televisão) e está passível de revelar as mudanças de significações da criança na cultura. Entendendo-se o termo cultura como "um conjunto de hábitos, práticas e sistemas de regras geradoras de textos" , os meios de comunicação de massa desempenham um papel importante "na medida em que agem como elementos ativos dessas mesmas estruturas, vinculando ou libertando as mensagens dentro das práticas produtivas e através delas" . Contextualmente, a televisão se apresenta como um agente de transformação não só de práticas determinantes para a elaboração da cultura e da realidade social da infância, mas também dos temas para a fabricação dos brinquedos; e o brinquedo, consequentemente, pode se apresentar como o meio pelo qual a metáfora do modo de presença da criança se materializa também na sociedade contemporânea ${ }^{6}$.

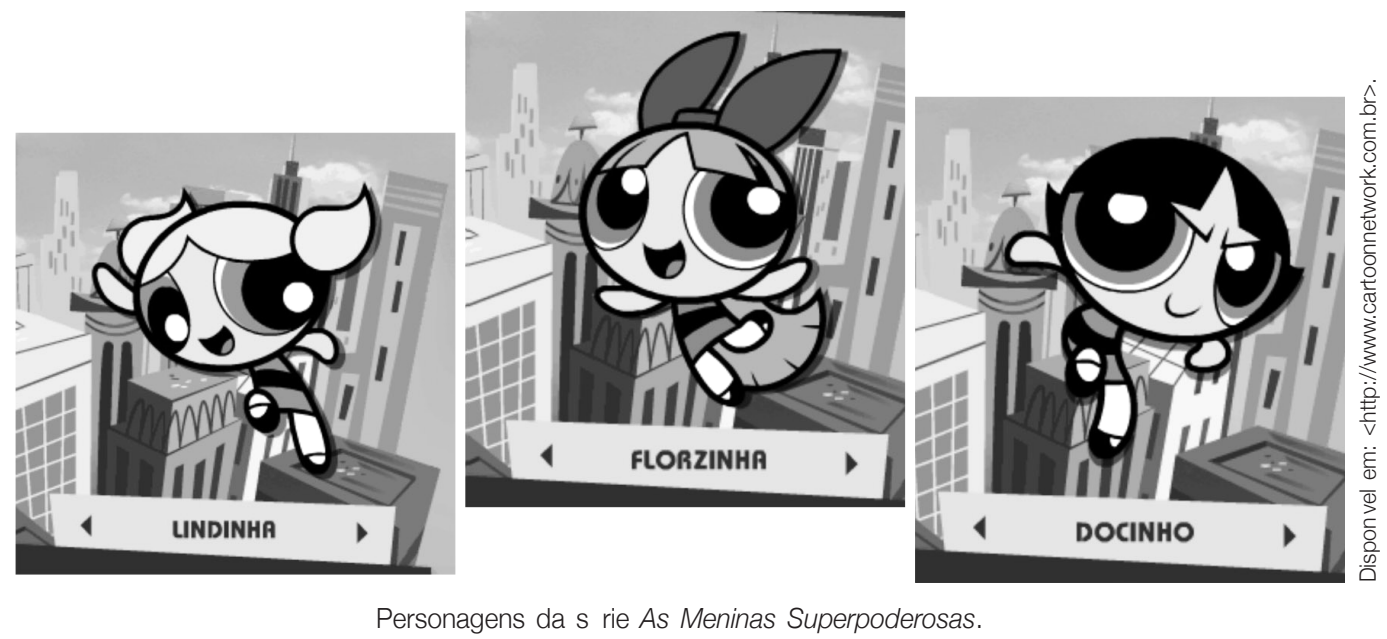

Personagens da s rie As Meninas Superpoderosas. 
Da ficção ao brinquedo, o discurso de referenciação pode então ser identificado em dois níveis: o primeiro, nos enunciados que circunscrevem a interioridade e a plasticidade das personagens no desenho animado; o segundo, nos enunciados narrativizados em cenários constantemente associados a ambientes urbanos e localidades de diversão e lazer em conjunção com os ambientes do próprio enunciatário infantil. Ou seja, as personagens assim manifestas por um desenho com vida na televisão simulam os ambientes e as rotinas das crianças espectadoras, intensificando os mecanismos de projeção/identificação: as crianças brincam de ser, encenam as atitudes, revestem-se dos superpoderes, demonstrando uma certeira relação afetiva com a imagem assistida.

Na substância desses brinquedos-personagens, imagens de plástico, de borracha, de pelúcia ou de papel, em materiais artificiais, ganham vida fora do écran, no imaginário infantil, situado em espaços também artificiais: shoppings, lojas de brinquedos, apartamentos, condomínios, escolas, parques temáticos lugares comuns da infância urbana.

\section{A REPRESENTAÇÃO SOCIAL ENTRE TELEVISÃO E INFÂNCIA: MEDIAÇÕES SIMBÓLICAS SUPERPODEROSAS?}

Como agentes de integração dessa família Superpoderosa, encontram-se as três heroínas, protagonistas da ficção narrativa ${ }^{7}$, instituídas do papel actancial crianças. Lindinha, Florzinha e Docinho nascem de um experimento químico do Professor Utônio, já com a idade aproximada de seis anos, e frequentam diariamente o nível correspondente ao jardim de infância da Escola de Townsville.

A representação criança integrante de uma família parece apontar a presença da infância na trama narrativa, além de reforçar as referências intertextuais atualizadas pelo espectador infantil por verossimilhança. No entanto, o que deixa perceber é um modo próprio de infância inaugurado pela contemporaneidade capaz de subverter os conceitos de um imaginário coletivo social datado no século XIX: “[...] até recentemente, uma das diferenças importantes entre crianças e adultos residia no fato de os adultos estarem de posse de informações
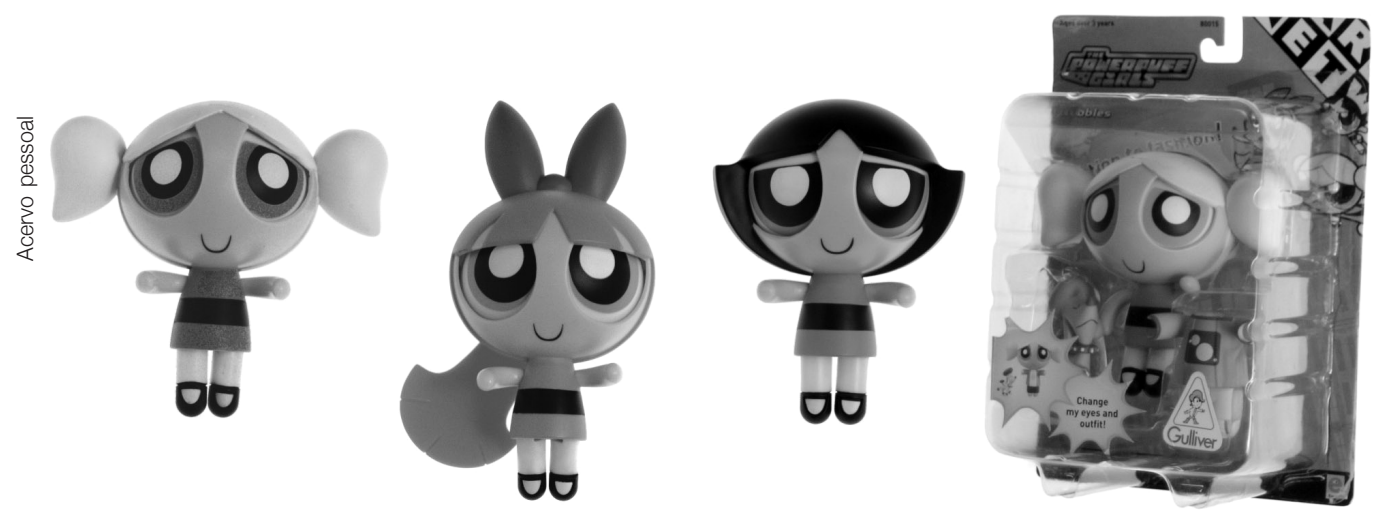

Cole

o particular. Bonecas Lindinha, Florzinha e Docinho. Modelo Super Faschion Doll Guliver
7. THE POWERPUFF Girls - The Movie (As Meninas Superpoderosas - o filme). Los Angeles: Warner Bros, 2004. 1 DVD. Cartoon Network Production. 
8. POSTMAN, N. O desaparecimento da infância. Rio de Janeiro: Graphia, 1999. p. 63.

9. Ibid.

10. ARIÉS, P. História social da criança e da família. Rio de Janeiro: Guanabara, 1986.

11. POSTMAN, N., op. cit., p. 94.

12. Ibid. que não eram consideradas adequadas às crianças"8. A ideia de infantilização que permeava o imaginário coletivo instituía uma atenuada diferença entre a idade adulta e a idade infantil. Ao restringir a criança ao conhecimento livresco e à supervisão de professores e pais, "fechou-se o mundo dos assuntos cotidianos com os quais os jovens estiveram tão familiarizados na Idade Média"9. O conhecimento desses segredos culturais passou a ser uma das características da idade adulta e, à medida que avançavam na idade, estes lhes eram revelados por etapas, culminando no esclarecimento sexual ${ }^{10}$. A criança era vista como um adulto informe que precisava ser civilizada, treinada nos moldes do adulto.

Em oposição a essa linha demarcada entre as fases infância e vida adulta, o que se pode observar, contemporaneamente, parece ser um rompimento dos padrões de infantilização, capacitando a criança a uma espécie de agente de transformação social participativo da vida adulta, o que a torna cada vez mais indiferenciada: ela decide, opina e conhece praticamente todos os assuntos do cotidiano.

Na trama ficcional, As Meninas Superpoderosas deixam-se corresponder ambiguamente a um conceito de infância que escapa de uma conceitualização bem definida. Se, por um lado, frequentam as práticas educacionais e moralistas da escola $^{11}$, vivenciando aprendizados e ações daquilo que se considerava próprio da infância, tal como brincar, conhecer em etapas, socializar, moralizar, por outro, estão instituídas da obrigação de salvar o dia todos os dias após irem à escola. $\mathrm{O}$ que se pode perceber é a instituição de um espaço in que se configura dentro do jardim de infância, permitindo às três heroínas Lindinha, Florzinha e Docinho agirem e se comportarem tal como crianças, de acordo com os conceitos antes permeados sobre a infância; e um espaço out, uma janela que se inaugura fora do jardim de infância, ou seja, um espaço fora do mundo infantilizado pelo imaginário social, no qual a elas passam a ser permitidas - e exigidas - atitude e participação, como agentes de transformação, nos problemas de ordem social. As heroínas transitam, assim, entre o mundo simbólico da criança e do adulto, dentro e fora do jardim de infância, compartilhando a linguagem, o aprendizado, os gostos, os apetites, a vida social de um adulto.

As Meninas Superpoderosas parecem metaforizar um modelo novo de infância, consolidado vagarosa e imperceptivelmente com o advento da mídia eletrônica. A presença especificamente da televisão nos lares a partir de 1950 inaugura o momento da acessibilidade da criança à informação controlada, desmistificando a aprendizagem sequencial. Torna-se "impossível reter qualquer segredo, [e] sem segredos, não pode haver infância" ${ }^{\text {"2 }}$, já que se trata de uma tecnologia para a qual não há restrições físicas, econômicas, cognitivas ou imaginativas. A televisão está então colocada como uma janela para o mundo, um espaço out disponível para todos independentemente da idade; como um espaço que se utiliza da imagem como linguagem, comportando significados cruciais e exigindo, sobretudo, habilidades elementares para ser compreendida:

[...] a televisão destrói a linha divisória entre a infância e adulto de três maneiras, todas relacionadas com sua acessibilidade indiferenciada: primeiro porque não 
A Dona da Brincadeira - Juliana Pereira de Sousa

requer treinamento para aprender sua forma, segundo porque não faz exigências complexas nem à mente nem ao comportamento, terceiro porque não segrega seu público ${ }^{13}$.

Dessa maneira, "vê-se um paradigma de uma estrutura social emergente que deve fazer desaparecer a infância"14. A janela que se abre em um espaço fora da escola frequentada pelas três heroínas na narrativa ficcional parece ser o espaço inaugurado também pela presença da televisão, eliminando a exclusividade do conhecimento mundano e, portanto, excluindo uma das principais diferenças entre a infância e a vida adulta.

Estas considerações permitem assim enfatizar a leitura das metáforas dos superpoderes a partir da trama ficcional: sopro de gelo e de chamas, raio infravermelho e amplo campo de visão, potência e velocidade para a corrida e para o salto. Mediando o mundo simbólico da criança e do adulto, as superforças apresentadas como habilidades específicas das personagens, se por um lado procuram distingui-las como heroínas das demais crianças figurativizadas no mundo imaginário da ficção, por outro as aproximam das potencialidades do mundo adulto, sobrepondo-as às condições do homem infante visto como um ainda não. Os superpoderes passam a ser a chave que permite a participação d'As Meninas Superpoderosas nas obrigações e responsabilidades da sociedade de Townsville. Encontram-se significantes, entre o nível da manifestação dos superpoderes e o fundamental, que articulam a leitura da criança contemporânea, diferenciando-as das demais determinações históricas antes estabelecidas pelo imaginário social: ela sabe mais, é mais esperta, determinada e ágil, observa mais, exige mais, é menos infantilizada pelo adulto e pelas instituições moralistas. Dessa maneira, na trama narrativa, permite-se incorporar à cidade de Townsville um novo olhar sobre a infância: a criança como sujeito de demandas legítimas, contemporânea de si mesma, sempre aberta ao novo. Ou seja, a criança como sujeito vivo e inventivo da História.

Por conseguinte, das histórias de personagens do gênero feminino, Lindinha, Florzinha e Docinho assumem uma outra vez a função de ruptura e proposta de modelos capazes de romper o paradigma da mulher encerrada em seu papel tradicional destinada à reprodução, a cuidar dos filhos e do marido ${ }^{15}$. As Meninas Superpoderosas, assim como a grande maioria das heroínas oriundas dos quadrinhos, acentuam a identidade feminina propondo uma oposição à que se restringia ao instinto materno, à vida doméstica, à pureza e à resignação.

Florzinha, Lindinha e Docinho validam um percurso de significação do gênero feminino capaz de adjetivá-lo: a imanência da feminilidade e da mulher autoprovedora representada em Lindinha, mais dedicada à casa e aos cuidados maternais; a autossuficiente revelada em Docinho, cuja personalidade está marcada pelo espírito de aventura e força física; e a autoconfiante presente em Florzinha, cuja sabedoria e perspicácia propõem soluções e estratégias para derrotar os inimigos.

Essas características determinantes das personagens são capazes de construir enunciados referentes à mulher moderna e independente, comumente veiculada

13. Ibid.

14. Ibid.

15. PRIORE, op. cit. 
comunicação \& educação • Ano XV • Número 1 • jan/abr 2010

pela mídia de massa na sociedade contemporânea, delineando um modelo neofeminista que entende a imagem da mulher no século XX como uma construção elaborada:

[...] não apenas sobre a reivindicação de igualdade em todos os domínios do masculino, mas também sobre a reivindicação da identidade feminina, sobre uma feminilidade existencial, que a contracultura ou revolução cultural contribui para afirmar ${ }^{16}$.

Nesse sentido e fazendo-se ainda como uma reiteração intertextual de heroínas antecessoras, As Meninas Superpoderosas têm por objetivo a luta, a aventura e as ações próprias do gênero masculino. Configuram-se como identidades e atores sociais de um discurso do feminino constituído, entre outros fatores, pela busca não apenas de igualdade de gênero, mas, sobretudo, de uma superação sobre o gênero masculino. Isto pode ser observado na narrativa, quando são intercaladas atitudes e fazeres culturalmente determinados para meninos e para meninas. As personagens participam do mercado de trabalho pela responsabilidade de salvar o mundo, diariamente intuídas de força física e de espírito de aventura. Organizam e arrumam o quarto como provedoras dedicadas ao lar. Frequentam a vida social na escola em grupos mistos de amizade e integram-se como em uma família constituída da presença apenas do pai - o que pode demonstrar a passagem da grande estrutura patriarcal para a família restrita, "as quais condicionam e favorecem a evolução da condição feminina"17.

Como em Luluzinha e Turma da Mônica, em As Meninas Superpoderosas a existência de três personagens (ou de uma turma) pode sugerir que, apesar de apresentarem facetas diferentes contextualizadas pela figurativização de aspectos da infância contemporânea, todas são comuns às crianças. Talvez, como se vários aspectos presentes na infância passassem dissociados, permitindo ao espectador infantil contemplar e elaborar uma de cada vez. Florzinha, a líder da relação parental das Superpoderosas é tão confiante e habilidosa quanto Luluzinha e Mônica, e, além de manter características semelhantes de personalidade, apresenta ainda um vestidinho rosa figurativizado por traços simples em formato trapézio, que lembra em muito suas colegas personagens mirins. Entretanto, poderes extranaturais lhes são atribuídos, enquanto Lulu e Mônica revelam apenas astúcias e características inerentes ao homem (diga-se, à criança). Em As Meninas Superpoderosas, as narrativas giram em torno de ações e lutas contra monstros que ameaçam a cidade de Townsville, enquanto em Luluzinha e Turma da Mônica as disputas (e lutas) restringem-se, geralmente, à relação menina versus menino.

16. MORIN, E. Cultura de massa no século $X X$. Rio de Janeiro: Forense Universitária, 2002. p. 169 , v. 1.

17. Ibid., p. 165.

\section{O NOVO OLHAR SOBRE BRINQUEDOS}

Se antigas reflexões sobre o brinquedo repousavam sobre conhecimentos do campo da psicoaprendizegam ou da socioantropologia, ele se propõe nesta investigação como um objeto de potencialidade comunicativa, atualizando a 
reflexão necessária e examinando novos contornos delineados entre a criança e a sociedade.

Ainda que seja substantivo, como objeto que se manipula e com o qual se interage, ou tornado verbo, como ato de brincar, o brinquedo constitui um meio superpoderoso, um suporte de mensagens culturalmente entendidas, representando uma possibilidade analítica a partir da qual se pode compreender a produção cultural dos diferentes momentos que compõem a trajetória humana e, consequentemente, de que tipo de identidade se trata de constituir.

Que tipo de identidade, portanto, os brinquedos-personagem tratam de constituir? Seja talvez a identidade de uma infância permeada de experiências simuladas em suportes midiáticos. Ou, então, a identidade de uma infância que se rende à lógica do consumo, do sistema de classes e do efêmero. Mas, sobretudo, a identidade de um homem que pode buscar no herói de sua infância a própria história, afinal, "para todo homem existe uma imagem que faz o mundo todo parar. Para quantos essa imagem não está em uma caixa de brinquedos?"18.

\section{REFERÊNCIAS BIBLIOGRÁFICAS}

ARIÉS, P. História social da criança e da família. Rio de Janeiro: Guanabara, 1986.

BENJAMIN, W. Reflexões sobre a criança, o brinquedo e a educação. São Paulo: Editora 34, 2002.

CINEMA inspira fabricantes. Folha de S. Paulo, São Paulo, 7 mar., 1998. Folhinha. MORIN, E. Cultura de massa no século XX. Rio de Janeiro: Forense Universitária, 2002. v. 1.

POSTMAN, N. O desaparecimento da infância. Rio de Janeiro: Graphia, 1999.

PRIORE, M. D. (Org.). História das crianças no Brasil. São Paulo: Contexto, 2000.

. História das mulheres no Brasil. São Paulo: Contexto, 2004.

SODRÉ, M. Antropológica do espelho. Rio de Janeiro: Vozes, 2002.

THE POWERPUFF Girls - The Movie (As Meninas Superpoderosas - o filme). Los Angeles: Warner Bros, 2004. 1 DVD. Cartoon Network Production.

WOLF, M. Teorias da comunicação. Portugal: Presença, 1999.
18. BENJAMIN, W. Reflexões sobre a criança, o brinquedo e a educação. São Paulo: Editora 34, 2002. p. 32. 


\section{Assine a revista Comunicação \& Educação}

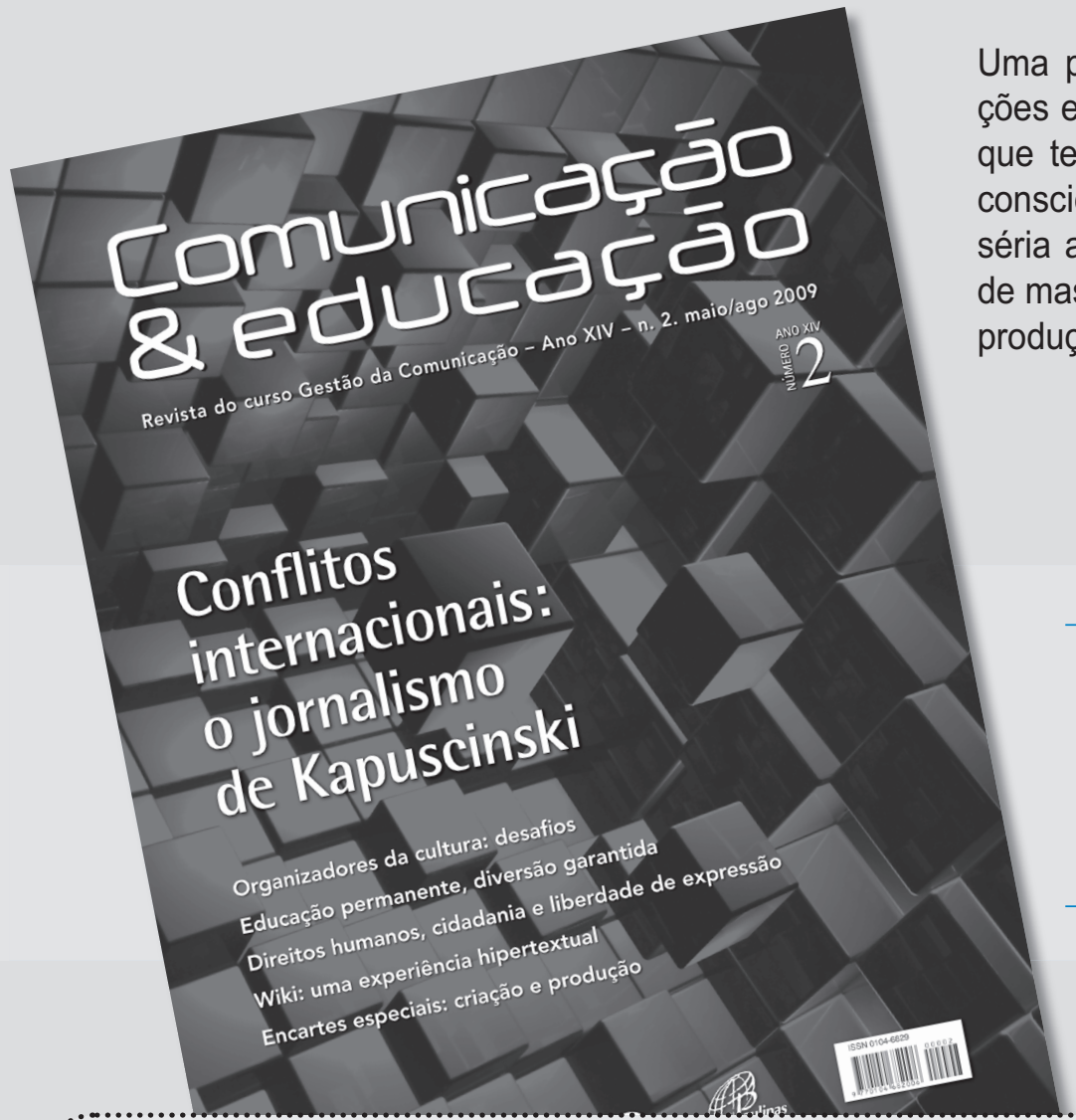

Uma parceria de Paulinas com a Escola de Comunicações e Artes, da Universidade de São Paulo (ECA-USP), que tem por objetivo ajudar a formar profissionais mais conscientes, críticos e interativos, por meio da discussão séria a respeito da natureza dos meios de comunicação de massa, dos direitos da audiência e da crítica estética à produção midiática.

\section{Revista Comunicação \& Educação}

Periodicidade: quadrimestral

\section{Ensaios, entrevistas e debates com os maiores especialistas da área auxiliam educadores a incluir em suas práticas novas linguagens e novos recursos pedagógicos.}

\section{ADQUIRA TAMBÉM OS EXEMPLARES AVULSOS!}
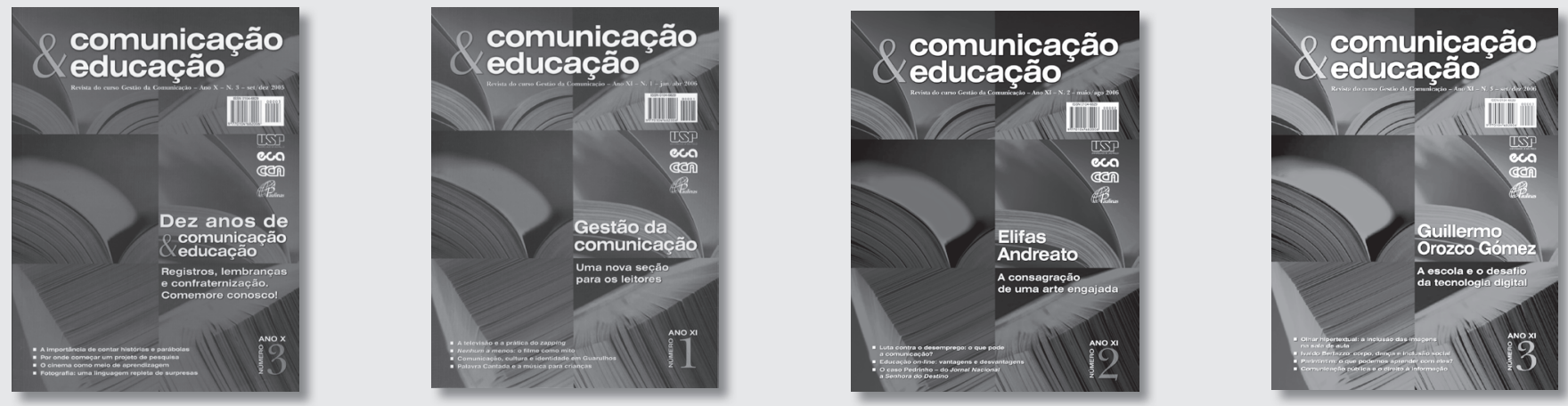

\section{VOCÉ ESCOLHE COMO QUER PAGAR!}

- Cartão de crédito - Visa, Mastercard ou Dinners • Boleto bancário

- Depósito bancário identificado - DOC ou transferência bancária

\section{Ligue 0800-7010081 ramal 9448 ou assine}

pela livraria virtual Paulinas, acessando www.paulinas.org.br Informações: livirtual@paulinas.com.br

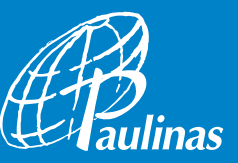

